\title{
RFID and GSM Based Safe Petrol Distribution System with Adulteration Prevention
}

\author{
Prof. Harsha Sarode, Sahil Mattoo, Supda Kate, Santosh Satam \\ Department of Electronics and Telecommunication Engineering, \\ NMIET, Talegaon Dabhade, Maharashtra, India
}

\begin{abstract}
How to cite this paper: Prof. Harsha Sarode | Sahil Mattoo | Supda Kate | Santosh Satam "RFID and GSM Based Safe Petrol Distribution System with Adulteration Prevention" Published in International Journal of Trend in Scientific Research and Development (ijtsrd), ISSN: 24566470, Volume-3 | Issue-3, April 2019, pp.1060-1064, URL: https://www.ijtsrd.c om/papers/ijtsrd23 129.pdf

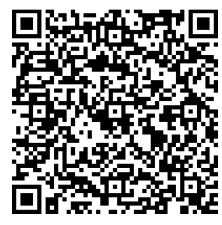
IITSRD23129

Copyright (C) 2019 by author(s) and International Journal of Trend in Scientific Research and Development Journal. This is an Open Access article distributed under the terms of the Creative Commons

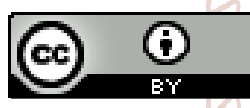
Attribution License (CC BY 4.0) (http://creativecommons.org/licenses/ by/4.0)
\end{abstract}

\section{INTRODUCTION}

Companies are moving towards automation today to increase the efficiency, quality and to reduce system manipulation by human. Fuel distribution is a task with high risk of security. The fuel is supposed to be secured from any thefts. Our system is capable of automating the process of fuel distribution. Our system provides safe transportation of fuel with accurate distribution as per fuel requirements of various Petrol pumps using RFID technology. The valves of the petrol tank used for transportation until the Petrol pump is authenticated. Also if there is any leakage in the tanker, it can be immediately identified by our system. Adulteration of fuel is very rampant; this is because the products of comparable quantities has different price. Nowadays fuel is being adulterated by the Petrol pump owners. These malpractices are affecting the environment and simultaneously affecting the vehicles. Fuel adulteration has many effects, especially on any vehicle that uses such fuel; there will be increase in the tailpipe emission of harmful pollutants that affects the environment and the human health. These practices are supposed to be stopped. Our system can detect the adulteration at the Petrol pumps. After detecting a foreign fluid in the petrol pump tank a message will be sent to the Petrol manufacturer, notifying the company about the adulteration along with the petrol pump code. The most significant factor responsible for adulteration is non-availability of real time institutional techniques that followed universally for forthwith detection of adulteration level. According to the reference paper "Estimation of petrol and diesel adulteration with kerosene and assessment of usefulness of selected automobile fuel quality test parameters" by Sh. R. Yadav, Adulteration can be detected using the fluid factors i.e. viscosity and density. RFID - Radio Frequency Identification is a technology for tagging using radio waves. According to reference paper "Fuel Pump Dispensing System" by Mr. Rohit K, RFID technology can be used for authentication.

A RFID tag is a small electronic device, supplemented with an antenna that can transmit and receive data. The RFID technology is designed for the unique identification of different kinds of objects. Due to their small size the RFID systems have a limited computational power, and limit memory there for a "heavy" encryption algorithm can't be used by RFID systems.

\section{MOTIVATION}

Due to increasing cases of adulteration in the society, this proposed system can be very beneficial. Fuel adulteration can affect the life of engines and also increase the environmental pollution. Fuel prices are increasing day by 
day in India and petrol pump owners try to increase their profit by performing such unethical practices. Theft or embezzlement of fuel causes loss to the petrol pump company. These problems can be prevented by the proposed system.

\section{LITERATURE SURVEY}

\section{FUEL ADULTERATION DETECTION SENSORS}

Difficulty in the composition of petroleum-derived fuels and their potential adulterants leads to a challenging situation where compliance and implementation of standard norms are not easy. Widely approved and adopted standard methods such as EN, ATSM, and ISO that encompass a variety of properties for testing fuels. There is no particular technique is precisely designed to assess the adulteration of fuel while most of these techniques are equally applicable to assess the adulteration of petrol and diesel fuels.

Due to price hike in petroleum products, adulteration is being observed everywhere. Suppliers could have profit about $10-15 \%$ by mixing petrol and various constituents. There are several sensors were designed to define theconcentration of adulteration in fuel samples.

\section{Fuel Adulteration detection sensor using IR sensor/imaging processing}

Jersha $\mathrm{V}$ and his co-workers have been described automatic fuel adulteration detection and reporting system. In this fuel adulteration detection technique, a sample of the fuel is heated to a temperature which is equal to the boiling point of the kerosene and petrol. In thecase of petrol, it is being heated to a temperature equal to the boiling point of petrol and in thecase of diesel, it is being heated to atemperature equal to the boiling point of kerosene. So that any one of the constituent fuel gets evaporated and another constituent fuel is left in the in the sample. For instance, in the case of diesel adulterated with kerosene, the constituent fuel left would be diesel. Similarly, in the case of petrol adulterated with kerosene, the constituent fuel left would be kerosene. From this study amount of the fuel adulteration can be detected. The quantity of the left-out sample after heating the adulterated fuel is detected by using two different techniques. The first technique employs Infrared (IR) sensors and the second technique employs camera based Imaging system for detection of sample level. At theend two techniques were compared and image processing technique has been given better results than IR detection technique.

\section{Fuel Adulteration detection sensor using Micro- controller (ARM)}

S.D. Kale et.al had described a micro-controller based technique for determination of adulteration concentration in the sample. In this technique, fuel adulteration has done by investigating various parameters such as viscosity and density are which are determined by experimental setup and whereas parameters such as temperature and humidity determined by using sensors. The determined test results were compared with standard references using ARM microcontroller which provides anoutput on LCD screen.

\section{Fuel adulteration detection sensor based on nonporous} silicon micro cavity

An optical sensor has been developed to estimate the amount of adulteration in fuel sample using a porous silicon microcavity which is fabricated using electrochemical anodization method. Reflectance quantities are used to estimate the concentration of kerosene which is the most frequently used fuel adulterant for diesel and petrol. The principle behind the sensing is based on the change in the effective refractive index of the silicon microcavity due to the fuel introduction into the pores leads to modification in the reflectance spectrum of the structure. This sensor also can be used for the detection of adulteration in both in diesel as well as petrol. The process of this sensor is reversible; thus, the sensor can be reusable.

\section{Simulation based fuel adulteration detection sensor} Rajan Dey et.al developed a device design using TSM BAW micro acoustic sensor with dual density-viscosity sensing and integrated temperature sensor in COMSOL Multiphysics v4.2 and analysed both AT and SC cut quartz resonators for comparison, and found that there is a shift in frequency response of the resonator whenever the density and viscosity are changing, this change in the resonant frequency is analysed to detect the amount of adulteration.

Fuel Adulteration detection sensor using highly sensitive electrical meta-material sensor

Vaishali R and her co-workershave developed a device which works based on the electric meta material concept, i.e. complementary split-ring resonator (CSSR), operating at 2.47GHz (The industrial, scientific, and medical radio band ISM band). This device is used to detect the kerosene adulteration in petrol. The sensor is a CSRR circuit, which exhibits sub-wavelength resonance having high sensitivity and Q-factor. Further, a Polydimethylsiloxane(PDMS) based sample cavity is designed for micro-quantity sensing to make the device more precise, sensitive and selective. A device operating at $2.47 \mathrm{GHz}$ is hence proposed for adulteration of kerosene in petrol, varying up to 30 per cent. Unadulterated samples (Standard samples) were derived from the Company operated Company owned petrol pump, and the adulterated samples were made in the laboratory for precise calibration. Systematic variations in the resonance frequency and magnitude were examined with adulterated fuels. The sensing measurements were done on Vector Network Analyser (VNA). The sensing was rapid and the recovery was almost instantaneous; ensuring a sensitive and accurate device for detection of adulteration in petrol.

\section{Fuel adulteration detection sensor using long period fiber grating technology}

Vandana M et.al depicted the capability of long-period fiber grinding (LPFG) sensor innovation to distinguish the nearness of $10 \%$ contaminant in automotive fuels utilizing LPFG method while the conventional advances can identify nearness of about over $20 \%$ of the same. LPFG technique involves the shift in the transmission spectra of the different proportions of the fuel and this shift is an index of the fuel quality.

Biofuel blending sensor using a microfluidic viscometer Sanket $\mathrm{G}$ et.al employed computational and the comparative experimental analysis of a micro fluidic device that examines the amount of blending by observing the interaction between the two fluid surfaces. Acrylic material with the help of well-established micro-fabrication technique. The viscosity of the different bio-diesel mixes can be utilized to demonstrate the part of bio-diesel in the fuel. The interface move is a direct result of the more prominent inhabitancy rate of a liquid having ahigher viscosity in the channel. 
Fuel adulteration detection sensor using turnaround point long period fiber gratings in $\mathrm{B} / \mathrm{Ge}$ doped fiber Sanjay K et.al recommended the utilization of turnaroundpoint long-period fiber gratings for wavelength encoded thelocation of adulteration in fuels, they have exhibited $\mathrm{CO} 2$ laser composedcorrect TAP-LPGs in B/Ge doped filaments for fuel adulteration recognition with high affectability of $0.96 \mathrm{~nm} / \%$ change of lamp fuel in gas. A normal grinding affectability of $1635 \mathrm{~nm} /$ RIU for SRI in the range 1.397 to 1.4372 has been illustrated.

Fuel adulteration detection sensor using silicon oxynitride based evanescent optical waveguide sensor Aradhana D et.al designed and fabricated a silicon oxynitride based Evanescent Optical wave guide sensor (EOWS) as the core layer on silica-silicon wafer and its operation for quick and easy detection of adulterants in petrol encompassing geometry of composite planar waveguide. The embedded waveguide of core width $\sim 50 \mu \mathrm{m}$ and length $\sim 10,000 \mu \mathrm{m}$ was fabricated using Reactive Ion Etching (RIE) and Plasma Chemical Vapour Deposition (PECVD) techniques. The vital aim of this sensor is to incorporate an abrupt choice to the time-consuming existing adulteration detection techniques which usually needs some time to give the consequence. Experimental results and theoretical predictions at wavelength $632.8 \mathrm{~nm}$ are investigated and displayed using Simple Effective Index Method(SEIM), which established that the sensitivity of the proposed (EWOS) is 20 times more than that of asymmetric wave guide structure and nearly 40 times more than that of existing planar wave guide sensors. thereby allowing rapid detection of adulterant constituents in petrol without using any chemicals[26].

\section{EXISTING SYSTEM}

According to surveys performed there's no such system installed on petrol pumps. To perform adulteration detection various laboratory tests are performed. No system is provided to check if the fuel is pure or adulterated.

\section{Disadvantages:}

$>$ Fuel quality on stake

$>$ Time consuming process

\section{FLOW CHART}

1. NODE 1

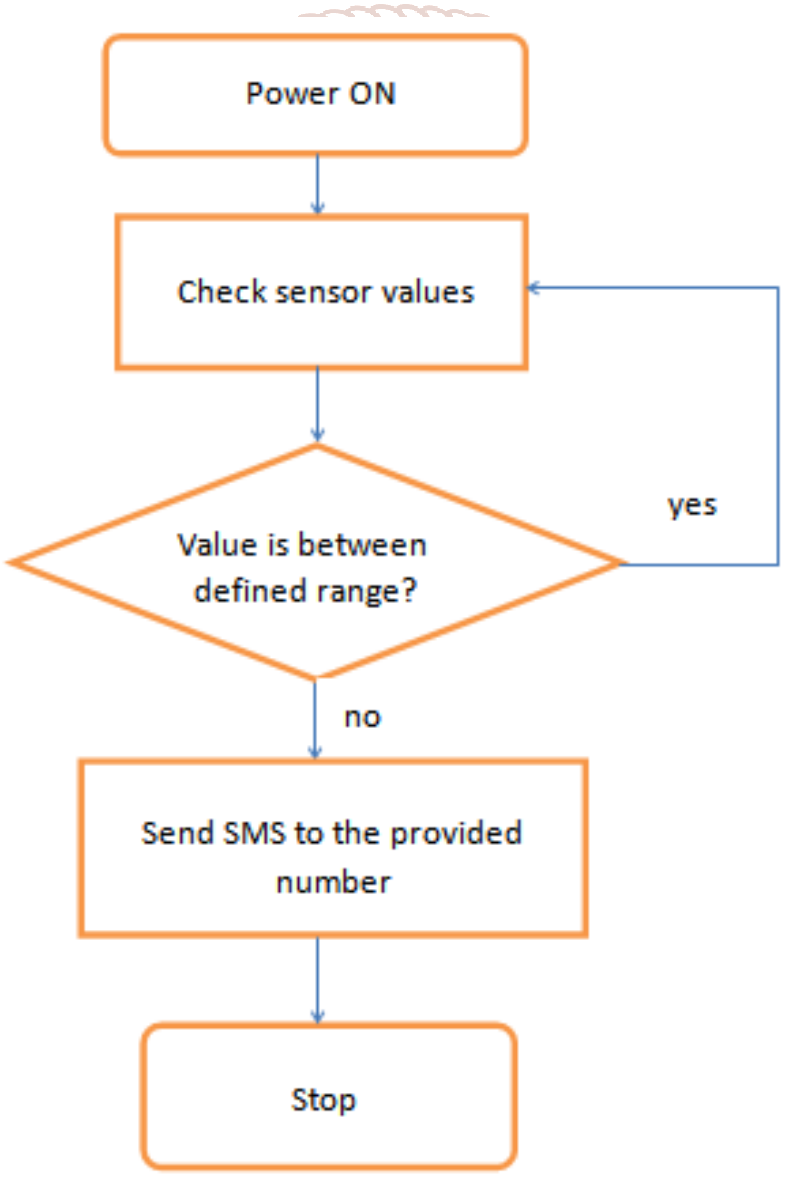


International Journal of Trend in Scientific Research and Development (IJTSRD) @ www.ijtsrd.com eISSN: 2456-6470

2. Node 2:

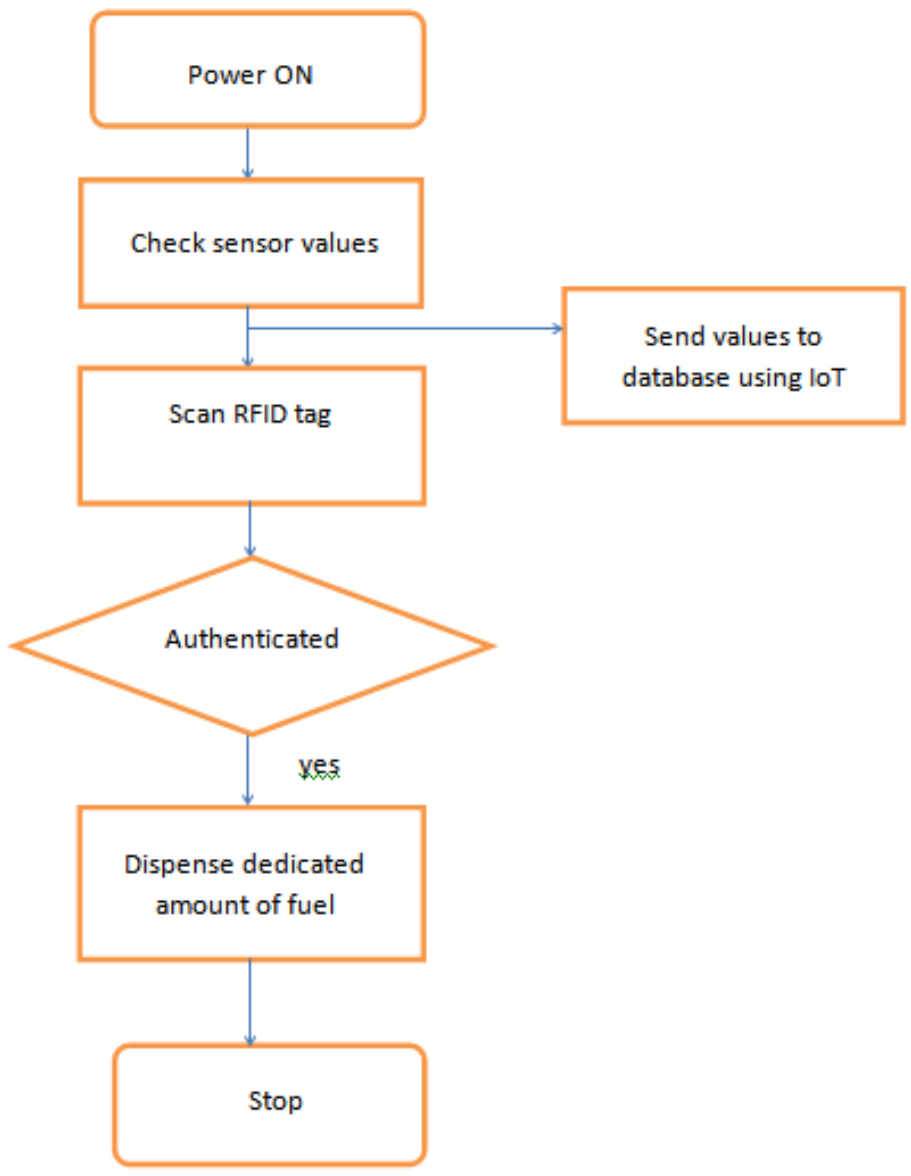

VI. ARCHITECTURE OF PROPOSED SYSTEM

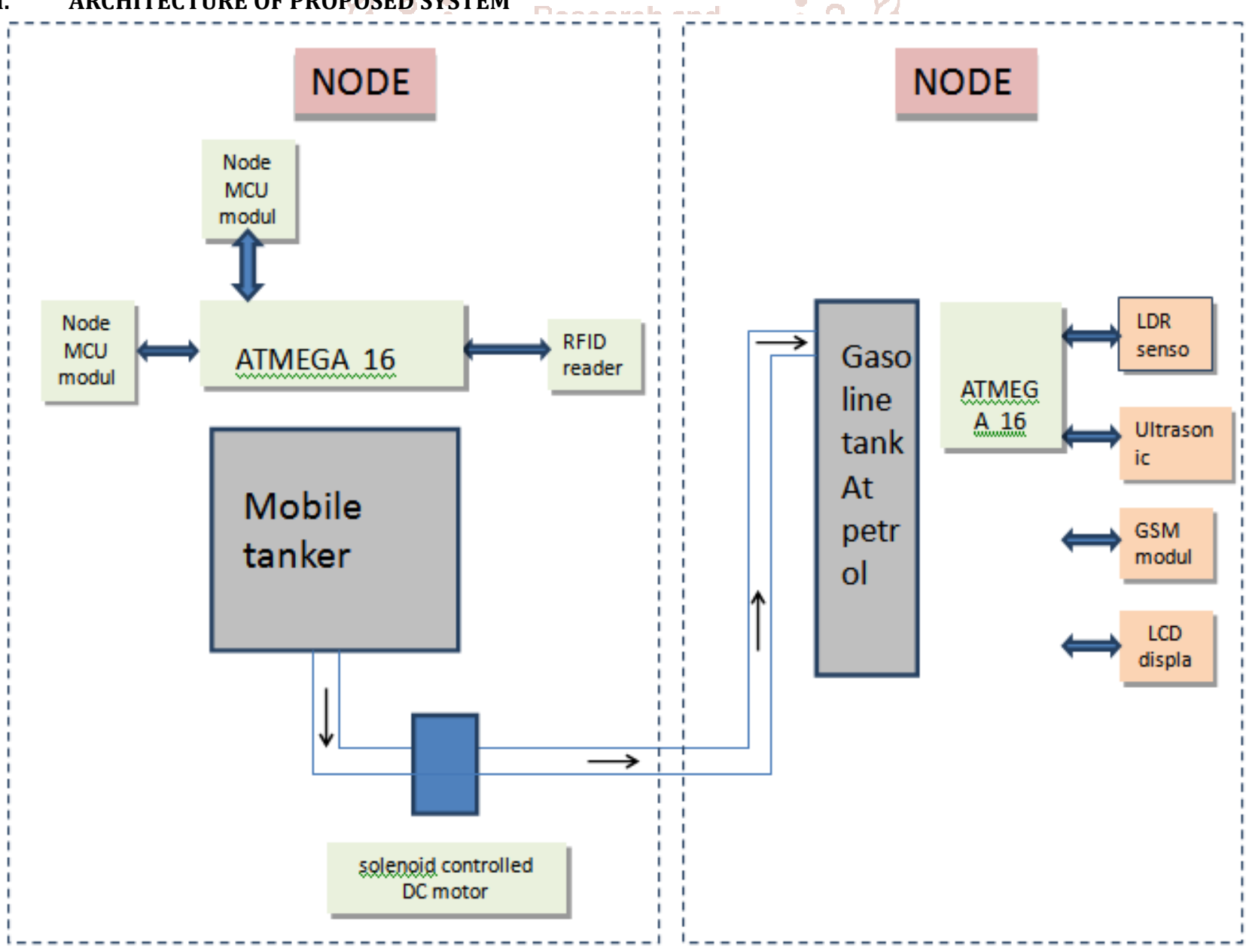




\section{PROPOSED SYSTEM}

The system has two nodes. One is the petrol pump node and another node is mobile tanker node.

Node1 (Petrol Pump):

This node is installed at a petrol pump. Here in the petrol tank there will be a sensor to check if adulteration has occurred or not. This is continuously monitored. If there is change in the value of sensor, then a message will be sent to the petrol pump owner. This indicates adulteration to the petrol pump company. Level sensor is present to monitor the level of fuel in tank. If the level of fuel in the tanker is less than a particular value which will be set by the petrol pump owner, then a message will be sent to petrol pump company in order to place an order of fuel.

Node2 (Mobile Tanker):

This node is installed in the tanker which is supposed to deliver the fuel to petrol pumps. There is a level sensor to monitor the level of fuel in tank. Continuously this level sensor data is provided to online database using IoT technology. This helps in keeping a check on fuel, and also helps in identifying embezzlement of fuel. RFID technology is used to authenticate the petrol pump. The fuel will be dispensed from the tank only if the RFID authentication occurs. It also helps in providing the dedicated amount of fuel to the petrol pump. This distribution is done with the help of pump.

\section{Advantages:}

$>$ Reduces Human Efforts

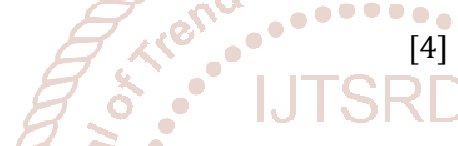

[4]

VIII. CONCLUSION

The proposed system is able to check the quality of the fuel. These observations are real time. Along with the purity check, the system provides a reliable fuel distribution system. This helps in reducing the error which occurs during distribution, reduces embezzlement of fuel and also reduces adulteration activities at petrol pumps. Such malicious activities can lead to cancellation of petrol pump license. The system is capable of automating the process of ordering fuel. This is not only beneficial for the petrol pump owner, but also for the company.

\section{REFERENCES}

[1] Sh. R. Yadav, "Estimation of petrol and diesel adulteration with kerosene and assessment of usefulness of selected automobile fuel quality test parameters" International Journal of Environmental Science \& Technology Vol. 1, No. 4, pp. 253-255, Winter 2005

[2] Prashant Kumar R. "TWO WHEELER VEHICLE SECURITY SYSTEM" International Journal of Engineering Sciences \& Emerging Technologies, Dec. 2013 Volume 6, Issue 3.

[3] Bhumi Bhatt, "Smart Vehicle Security System Using GSM \& GPS" International Journal of Engineering and Computer Science Volume 4 Issue 6 June 2015.

K. A. Amusa "DESIGN OF SMS-ENABLED CAR SECURITY SYSTEM" Transnational Journal of Science and Technology, Volume 2 November 2012.

> Reduces Adulteration Process And Helps To Prevent it.

$>$ Smart Distribution System Saves Manpower And Human Efforts.

and manement.

$>$ Easy petroleum distribution and management.

$>$ Secure petrol transactions.

Provides control over third party distributors.
[5] http://www.atmel.com/images/doc2503.pdf

[6] http://www.sunrom.com/p/16x2-lcd-black-on-yellow 